\title{
Interdigitating arch reconstruction eliminates recurrent coarctation after the Norwood procedure
}

\author{
Harold M. Burkhart, MD, ${ }^{a}$ David A. Ashburn, MD, ${ }^{c}$ Igor E. Konstantinov, MD, PhD, ${ }^{c}$ Nilto C. De Oliviera, MD, \\ Lee Benson, MD, William G. Williams, $\mathrm{MD}^{\mathrm{c}}{ }^{\mathrm{c}}$ and Glen S. Van Arsdell, $\mathrm{MD}^{\mathrm{c}}$
}

Background: We sought to determine whether evolving techniques of aortic arch reconstruction used during the Norwood procedure decreased the incidence of postoperative aortic arch obstruction.

Methods: Our technique for aortic arch reconstruction in patients undergoing the Norwood procedure has evolved from using an allograft patch (classic group, $\mathrm{n}=$ 26) to primary connection of the pulmonary artery and arch (autologous group, $\mathrm{n}=$ 20). More recently, we have used a novel technique involving coarctation excision, an extended end-to-end anastomosis on the back of the arch, and a counterincision on the anterior descending aorta to sew in an allograft patch for total arch reconstruction (interdigitating group, $\mathrm{n}=33$ ). Cardiac catheterizations performed before stage II palliation were reviewed for aortic diameters at multiple levels in 79 infants (median age, 4.2 months). Aortic arch obstruction was defined as a ratio between the diameters of the arch anastomosis and the descending aorta (coarctation index) of less than 0.7 .

Results: Overall, 15 (19\%) children had aortic arch obstruction. All 15 required aortic intervention (balloon angioplasty, $\mathrm{n}=12$; surgical patch angioplasty, $\mathrm{n}=2$; both, $\mathrm{n}=1$ ). Aortic arch obstruction rates for the classic, autologous, and interdigitating groups were $46 \%(\mathrm{n}=12), 15 \%(\mathrm{n}=3)$, and $0 \%$, respectively $(P>$ $.001)$.

Conclusion: Reconstruction of the aortic arch with excision of ductal and coarctation tissue is associated with lower aortic arch obstruction rates in patients undergoing the Norwood procedure. Arch reconstruction with a novel interdigitating technique decreases the incidence of aortic arch obstruction.

From the Department of Cardiothoracic Surgery, ${ }^{\mathrm{a}}$ University of Iowa Hospital and Clinics, Iowa City, Iowa, and the Division of Cardiovascular Surgery ${ }^{\mathrm{b}}$ and the Section of Pediatric Cardiology, ${ }^{\mathrm{c}}$ Hospital for Sick Children, Toronto, Ontario, Canada.

Received for publication June 15, 2004; revisions received Nov 15, 2004; accepted for publication Feb 22, 2005.

Address for reprints: Harold M. Burkhart, MD, University of Iowa, Department of Cardiothoracic Surgery, 200 Hawkins Dr, 1603 JCP, Iowa City, IA 52242 (E-mail: harold-burkhart@uiowa.edu).

J Thorac Cardiovasc Surg 2005;130:61-5

$0022-5223 / \$ 30.00$

Copyright $\odot 2005$ by The American Association for Thoracic Surgery

doi:10.1016/j.jtcvs.2005.02.060
$\mathrm{A}$ ortic arch obstruction (AAO) after the Norwood procedure has been reported to be as high as $20 \%$ to $36 \%{ }^{1-5}$ and is a significant cause of morbidity and mortality. From a clinical standpoint, postoperative neoaortic obstruction causing increased afterload can result in ventricular dysfunction, poor systemic output, and tricuspid regurgitation. Prior reports suggest that $7 \%$ to $8 \%$ of deaths after the Norwood procedure might be attributable to AAO. ${ }^{6,7}$ Since the Norwood procedure's original description, ${ }^{8}$ several modifications of arch reconstruction have been described. The purpose of this study was to determine whether there were AAO differences among 3 distinct arch reconstruction techniques used at the Hospital for Sick Children, Toronto, Ontario, Canada.

\section{Patients and Methods}

We reviewed infants who underwent the Norwood procedure and survived to stage II palliation at the Hospital for Sick Children, Toronto, between February 1991 and December 2002. During this period, our technique for aortic arch reconstruction in patients undergoing the Norwood procedure has evolved. Early in our experience, we incised across the coarctation and used a homograft patch to reconstruct the coarctation site, as well as the 


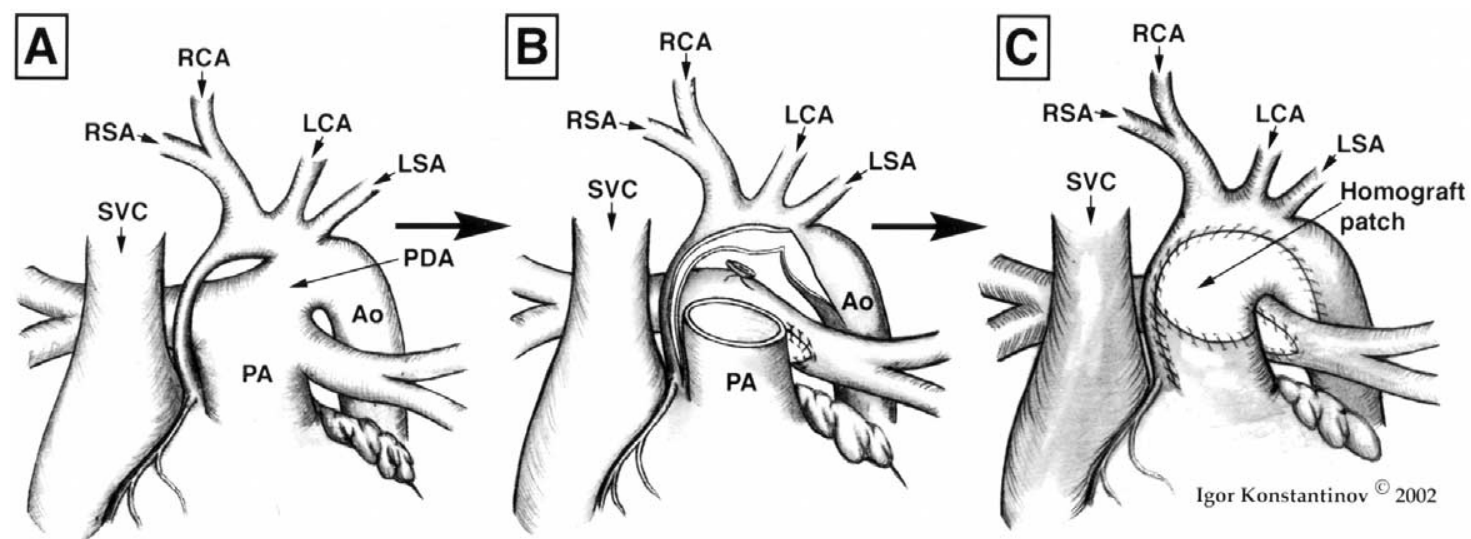

Figure 1. Classic technique. The arch anatomy is examined (A), the patent ductus arteriosus is ligated, and an incision is made across the coarctation (B). The aortic arch is reconstructed with a homograft patch (C). Ao, Aorta; $L C A$, left carotid artery; $L S A$, left subclavian artery; $P A$, pulmonary artery; $P D A$, patent ductus arteriosus; $R C A$, right carotid artery; $R S A$, right subclavian artery; $S V C$, superior vena cava.

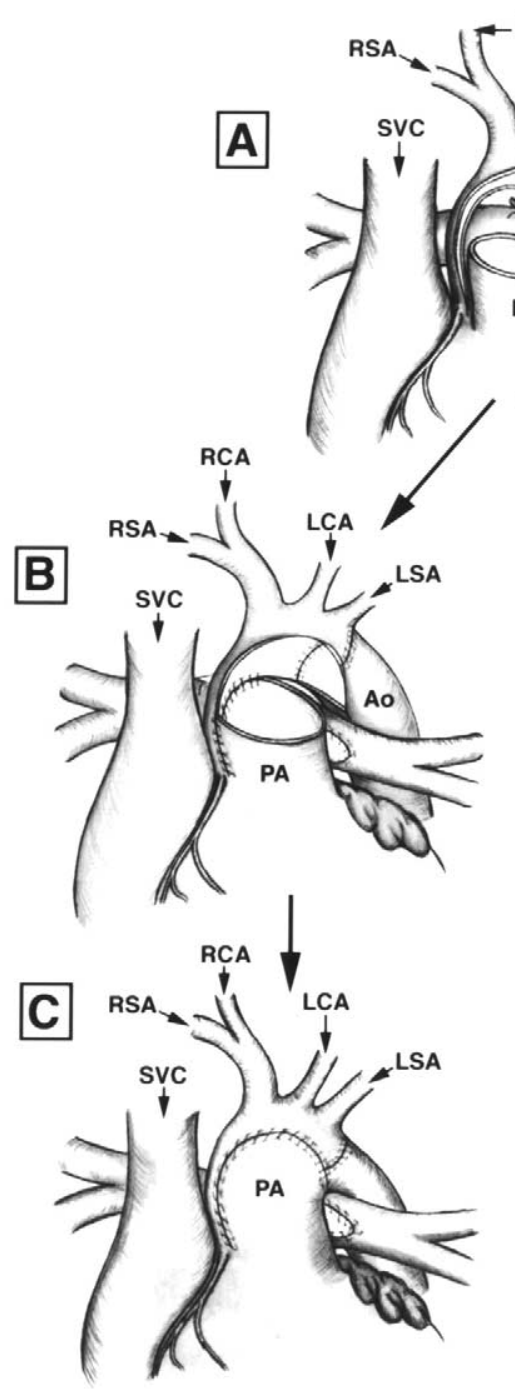

Figure 2. Autologous and interdigitating techniques. An incision is made across the coarctation (A), and the periductal area is completely excised. In the autologous technique ( $B$ and $C$ ) the arch is reconstructed by anastomosing the aortic arch, distal aorta, and main pulmonary artery together. In the interdigitating technique (B1 and C1) 2 longitudinal incisions are made in the anterior and posterior walls of the descending aorta (B1.a), and an extended end-to-end anastomosis is constructed between the distal aortic arch and the posterior descending aorta (B1). A homograft patch is then used to reconstruct the remainder of the arch (C1). Ao, Aorta; LCA, left carotid artery; $L S A$, left subclavian artery; $P A$, pulmonary artery; $R C A$, right carotid artery; $R S A$, right subclavian artery; SVC, superior vena cava.

62 The Journal of Thoracic and Cardiovascular Surgery • July 2005 
TABLE 1. Diagnoses of 79 patients undergoing the Norwood procedure

\begin{tabular}{lr}
\hline Diagnosis & $\mathbf{n}(\%)$ \\
\hline Hypoplastic left heart syndrome & $50(63)$ \\
Tricuspid atresia & $9(11)$ \\
Transposition of the great arteries & $7(8.8)$ \\
Aortic stenosis & $3(3.8)$ \\
Atrioventricular septal defect & $2(2.5)$ \\
Double-outlet right ventricle & $2(2.5)$ \\
Hypoplastic aortic arch & $2(2.5)$ \\
Interrupted aortic arch & $1(1.3)$ \\
Mitral stenosis & $1(1.3)$ \\
Truncus arteriosus & $1(1.3)$ \\
Univentricular heart & $1(1.3)$ \\
\hline
\end{tabular}

hypoplastic arch (classic group, $\mathrm{n}=26$; Figure 1). Beginning in 1998, we opted to excise the coarctation and ductal tissue before reconstruction. The arch was reconstructed by anastomosing the distal aorta, aortic arch, and main pulmonary artery together, as described by Fraser and $\mathrm{Mee}^{9}$ (autologous group, $\mathrm{n}=20$; Figure 2). More recently, we have used a novel technique involving complete coarctation excision with an extended end-to-end anastomosis on the back of the arch. A 1- to 2-cm counterincision is made on the anterolateral aspect of the descending aorta. A homograft patch is sutured from the descending aorta along the underside of the arch to the ascending aorta for total arch reconstruction (interdigitating group, $\mathrm{n}=33$; Figure 2).

Primary diagnoses for the overall cohort are shown in Table 1, with a majority having hypoplastic left heart syndrome. Of the 50 patients with hypoplastic left heart syndrome, 12 had aortic atresia. Demographic characteristics for each of the 3 surgical technique groups are shown in Table 2 .

Cardiac catheterizations performed before stage II palliation were reviewed to obtain aortic diameter in 5 locations. The following angiographic measurements were taken: aorta at the level of the ascending aorta, transverse arch, left subclavian artery, distal neoaortic anastomosis, and descending aorta. Coarctation index (CI) was calculated as the ratio of the distal neoaortic anastomosis to the descending aorta. ${ }^{10,11} \mathrm{AAO}$ was defined as a CI of less than $0.7{ }^{11}$ Patient records, subsequent angiograms, and operative reports were reviewed for AAO intervention.

Data are described as frequencies, medians with ranges, or means with SDs as appropriate. Intergroup comparisons were made by using $\chi^{2}$ or Fisher exact tests for categoric variables and $t$ tests or analysis of variance for continuous variables. General linear regression was used to define associations between continuous variables and CI, and multiple linear regression allowed comparison of CI after accounting for baseline differences among groups. All statistical analyses were performed with SAS Version 8 statistical software (SAS Institute, Inc, Cary, NC).

\section{Results}

Aortic angiographic measurements are shown in Table 3. The aorta at the level of the transverse arch and the left subclavian artery was significantly larger in the interdigitating group compared with in the classic group. However, the size of the aorta at the distal neoaortic anastomosis was similar in all 3 groups.

CIs for the classic, autologous, and interdigitating groups were $0.68 \pm 0.21,0.91 \pm 0.16$, and $1.1 \pm 0.16$, respectively $(P>.001)$. After accounting for age at the time of the Norwood procedure, weight, and sex, the autologous group had a higher $\mathrm{CI}$ than the classic group $(P>.001)$, and the interdigitating group had a significantly higher CI than both the classic $(P>.001)$ and autologous $(P=.002)$ groups.

Overall, 15 (19\%) children had AAO requiring intervention. The mean gradient for the AAO at cardiac catheterization was $21.3 \pm 13.3 \mathrm{~mm} \mathrm{Hg}$. Diagnoses of the patients requiring intervention were hypoplastic left heart syndrome in 12 patients ( 1 with aortic atresia), transposition of the great arteries in 1 patient, mitral stenosis in 1 patient, and univentricular heart in 1 patient. AAO rates for the classic, autologous, and interdigitating groups were $46 \%(\mathrm{n}=12)$, $15 \%(\mathrm{n}=3)$, and $0 \%$, respectively $(P>.001)$. Thirteen of the 15 children with AAO were treated with percutaneous balloon angioplasty. Three of these children required repeat balloon dilation. Three children ( 1 after balloon angioplasty and 2 as primary treatment) were treated surgically with a patch angioplasty at the time of stage II palliation. Table 4 demonstrates the variables associated with postoperative AAO. Arch reconstruction technique, as well as distal neoaortic anastomosis size, descending aorta size, and CI, were all significantly associated with postoperative AAO.

\section{Discussion}

AAO of the distal neoaortic anastomosis after the Norwood procedure is a frequently reported complication. Starnes and

TABLE 2. Demographic comparison of 79 patients who had 3 types of aortic arch reconstruction in the Norwood procedure

\begin{tabular}{|c|c|c|c|c|}
\hline & $\begin{array}{l}\text { Classic } \\
(n=26)\end{array}$ & $\begin{array}{c}\text { Autologous } \\
(\mathrm{n}=20)\end{array}$ & $\begin{array}{l}\text { Interdigitating } \\
\quad(\mathbf{n}=33)\end{array}$ & $P$ value \\
\hline Male sex $(\%)$ & $19(73)$ & $17(85)$ & $20(61)$ & .166 \\
\hline Age at Norwood procedure (d), median (range) & $6(2-45)$ & $6(2-60)$ & $10(2-135)$ & .81 \\
\hline HLHS $(\%)$ & $19(73)$ & $10(50)$ & $21(64)$ & .273 \\
\hline Weight at cardiac catheterization $(\mathrm{kg})$, mean \pm SD & $6.6 \pm 2.3$ & $5.4 \pm 1.4$ & $4.9 \pm 1.2$ & $.005^{*}$ \\
\hline Time from Norwood procedure to cardiac catheterization (d), mean \pm SD & $163 \pm 163$ & $135 \pm 68$ & $98 \pm 48$ & .06 \\
\hline
\end{tabular}

HLHS, Hypoplastic left heart syndrome; $S D$, standard deviation. *The classic group is heavier than the autologous and interdigitating groups. 
TABLE 3. Mean aortic angiographic measurements after the Norwood procedure

\begin{tabular}{lrccc}
\hline & $\begin{array}{c}\text { Classic } \\
(\mathbf{n}=\mathbf{2 6})\end{array}$ & $\begin{array}{c}\text { Autologous } \\
(\mathbf{n}=\mathbf{2 0})\end{array}$ & $\begin{array}{c}\text { Interdigitating } \\
(\mathbf{n}=\mathbf{3 3})\end{array}$ & $\boldsymbol{P}$ value \\
\hline AA (mm) & $18.5 \pm 4.4$ & $14.9 \pm 2.1$ & $16.8 \pm 4.2$ & $.0086^{*}$ \\
TA (mm) & $15.3 \pm 4.0$ & $11.8 \pm 3.0$ & $14.6 \pm 3.2$ & $.0029 \dagger$ \\
SA (mm) & $11.2 \pm 2.8$ & $9.6 \pm 2.8$ & $11.1 \pm 2.0$ & $.0493 \dagger$ \\
AnA (mm) & $7.2 \pm 2.7$ & $7.3 \pm 1.8$ & $8.4 \pm 2.1$ & .0884 \\
DA (mm) & $10.6 \pm 2.3$ & $8.1 \pm 1.9$ & $7.8 \pm 2.3$ & $<.0001 \ddagger$
\end{tabular}

$A A$, Ascending aorta; $T A$, transverse arch; $S A$, aorta at the level of the left subclavian artery; $A n A$, distal neoaortic anastomosis; $D A$, descending aorta. *No specific intergroup comparisons showed significance. †Autologous group versus interdigitating and classic groups. $\ddagger$ Classic group versus interdigitating group.

colleagues $^{4}$ and Zellers ${ }^{5}$ have reported AAO rates of $33 \%$ and $36 \%$, respectively. Because most children undergoing the Norwood procedure already have decreased ventricular function, it is understandable that AAO is not well tolerated. By increasing afterload, ventricular function and tricuspid regurgitation worsen, whereas systemic blood flow decreases. Coronary flow is compromised after an increase in systole time. Increased stress on a single right ventricle with shunt-dependant physiology is poorly tolerated. Fraisse and associates $^{2}$ reported a higher risk of death in Norwood survivors who had AAO compared with those who did not (relative risk, 5.9). In addition, treatment of AAO with balloon dilation has inherent risk. Tworetzky and cowork- ers $^{1}$ reported $2(25 \%)$ of 8 patients requiring cardiopulmonary resuscitation and inotropic support after cardiac decompensation during balloon angioplasty.

Several theories exist as to the cause of AAO after the Norwood procedure. Contributing factors include residual ductal tissue and surgical technique. Machii and Becker ${ }^{12}$ examined the histology of 5 hypoplastic left heart specimens. In 4 specimens they found ductal tissue extending into the aorta both proximally and distally from the ductal orifice. They concluded that coarctation was due to this extension and emphasized the importance of aortic augmentation beyond the site of coarctation. In children in whom we did not excise the coarctation tissue (classic group), the AAO rate was significantly higher (46\%) than in the groups in which ductal tissue was excised (autologous [15\%] and interdigitating [0\%] groups). We strongly believe that complete coarctation excision is one of the keys to avoiding postoperative AAO.

Even if the ductal tissue is grossly resected, AAO can occur. The interdigitating technique herein described provides a tapering distal anastomosis, with any potential residual ductal tissue being split longitudinally in an anterior and posterior position. The longitudinal incisions are augmented with autologous tissue posteriorly and pulmonary homograft anteriorly, hence the interdigitating designation.

The limitations of this study should be addressed. As Table 2 demonstrates, the time from the Norwood procedure to cardiac catheterization was least in the interdigitating

TABLE 4. Association of variables with postoperative aortic arch obstruction and their univariable significance

\begin{tabular}{|c|c|c|c|}
\hline Variable & Obstruction (n = 15) & No obstruction $(n=64)$ & $P$ value \\
\hline Sex & & & .69 \\
\hline Male $(n=56)$ & $10(18 \%)$ & $46(82 \%)$ & \\
\hline Female ( $n=23$ ) & $5(22 \%)$ & $18(78 \%)$ & \\
\hline Diagnosis & & & .23 \\
\hline HLHS $(n=50)$ & $12(24 \%)^{*}$ & $38(76 \%)$ & \\
\hline Non-HLHS $(n=29)$ & $3(10 \%)$ & $26(90 \%)$ & \\
\hline Anastomotic technique & & & $<.001$ \\
\hline Classic $(n=26)$ & $12(46 \%)$ & $14(54 \%)$ & \\
\hline Autologous ( $\mathrm{n}=20$ ) & $3(15 \%)$ & $17(85 \%)$ & \\
\hline Interdigitating $(\mathrm{n}=33)$ & $0(0 \%)$ & $33(100 \%)$ & \\
\hline Mean age at Norwood procedure (d) & $8 \pm 11$ & $14 \pm 23$ & .34 \\
\hline \multicolumn{4}{|l|}{ Mean catheterization variables } \\
\hline Time from Norwood procedure (d) & $180 \pm 206$ & $117 \pm 63$ & .12 \\
\hline Age (d) & $189 \pm 205$ & $131 \pm 63$ & .14 \\
\hline Weight (kg) & $6.2 \pm 2.8$ & $5.3 \pm 1.3$ & .15 \\
\hline Ascending aorta (mm) & $16.5 \pm 3.8$ & $17.0 \pm 4.1$ & .66 \\
\hline Transverse arch (mm) & $13.0 \pm 3.4$ & $14.4 \pm 3.7$ & .18 \\
\hline Aorta at left subclavian (mm) & $9.6 \pm 3.1$ & $11.0 \pm 2.3$ & .06 \\
\hline Aorta at distal anastomosis (mm) & $5.5 \pm 2.1$ & $8.3 \pm 2.0$ & $<.001$ \\
\hline Descending aorta (mm) & $10.3 \pm 2.8$ & $8.5 \pm 2.4$ & .02 \\
\hline Coarctation index & $0.55 \pm 0.19$ & $0.99 \pm 0.17$ & $<.001$ \\
\hline
\end{tabular}

HLHS, Hypoplastic left heart syndrome. *There was 1 patient with aortic atresia. 
group. Whether this earlier catheterization time could have influenced the recoarctation rate cannot be said for certain. Table 2 shows that the descending aorta in the classic group was significantly larger than in the interdigitating group. This could possibly be due to poststenotic dilation. This increased number would decrease the CI. Of note is that the decision to intervene was based not just on the CI but also on angiographic appearance, as well as hemodynamics. Another limitation is the lack of complete hemodynamic data on the patients without AAO. However, Lemler and colleagues ${ }^{11}$ demonstrated that the CI correctly predicted a nonobstructed aortic arch in all of their patients without AAO. Furthermore, their CI correlated with their cathetermeasured gradients $(r=-0.78, P>.001)$. Nonetheless, having the complete hemodynamic data might have provided more insight.

In conclusion, excision of the ductal and coarctation tissue and the use of an interdigitating repair during Norwood arch reconstruction are associated with decreased AAO rates. Our novel technique of reconstruction with an interdigitating anastomosis decreases postoperative AAO.

\section{References}

1. Tworetzky W, McElhinney DB, Burch GH, Teitel DF, Moore P. Balloon arterioplasty of recurrent coarctation after the modified Norwood procedure in infants. Catheter Cardiovasc Interv. 2000;50:54-8.
2. Fraisse A, Colan SD, Jonas RA, Gauvreau K, Geva T. Accuracy of echocardiography for detection of aortic arch obstruction after stage I Norwood procedure. Am Heart J. 1998;135:230-6.

3. Ishino K, Stumper O, De Giovanni JJV, et al. The modified Norwood procedure for hypoplastic left heart syndrome: early to intermediate results of 120 patients with particular reference to aortic arch repair. J Thorac Cardiovasc Surg. 1999;117:920-30.

4. Starnes VA, Griffin ML, Pitlick PT, et al. Current approach to hypoplastic left heart syndrome: palliation, transplantation, or both? J Thorac Cardiovasc Surg. 1992;104:189-95.

5. Zellers TM. Balloon angioplasty for recurrent coarctation of the aorta in patients following staged palliation for hypoplastic left heart syndrome. Am J Cardiol. 1999;84:231-3.

6. Bartram U, Grunenfelder J, Van Praagh R. Causes of death after the modified Norwood procedure: a study of 122 postmortem cases. Ann Thorac Surg. 1997;64:1795-802.

7. Weinberg PM, Chin AJ, Murphy JD, Pigott JD, Norwood WI. Postmortem echocardiography and tomographic anatomy of hypoplastic left heart syndrome after palliative surgery. Am J Cardiol. 1986;58: 1228-32.

8. Norwood WI, Lang P, Hansen DD. Physiologic repair of aortic atresiahypoplastic left heart syndrome. N Engl J Med. 1983;308:23-5.

9. Fraser CD, Mee RBB. Modified Norwood procedure for hypoplastic left heart syndrome. Ann Thorac Surg. 1995;60(suppl):S546-9.

10. Ramaciotti C, Chin AJ. Noninvasive diagnosis of coarctation of the aorta in the presence of a ductus arteriosus. Am Heart J. 1993;125: 179-85.

11. Lemler MS, Zellers TM, Harris KA, Ramaciotti C. Coarctation index: identification of recurrent coarctation in infants with hypoplastic left heart syndrome after the Norwood procedure. Am J Cardiol. 2000;86: 697-9.

12. Machii M, Becker AE. Nature of coarctation in hypoplastic left heart syndrome. Ann Thorac Surg. 1995;59:1491-4. 